\title{
Determinants of endothelial function in patients with COPD
}

\author{
Christian F. Clarenbach¹, Oliver Senn², Noriane A. Sievi', Giovanni Camen', \\ Arnoldus J.R. van Gestel', Valentina A. Rossi', Milo A. Puhan ${ }^{3}$, \\ Robert Thurnheer ${ }^{4}$, Erich W. Russi ${ }^{1,5}$ and Malcolm Kohler ${ }^{1,5}$
}

Affiliations: ${ }^{1}$ Pulmonary Division, University Hospital Zurich, Zurich, ${ }^{2}$ Institute of General Practice and Health Services Research, University of Zurich, Zurich, "Pulmonary Division, Cantonal Hospital of Muensterlingen, Muensterlingen, and ${ }^{5} \mathrm{C} e n t r e$ for Integrative Human Physiology, University of Zurich, Zurich, Switzerland. ${ }^{3}$ Dept of Epidemiology, Johns Hopkins Bloomberg School of Public Health, Baltimore, MD, USA.

Correspondence: M. Kohler, Pulmonary Division, University Hospital of Zurich, Raemistrasse 100, 8091 Zurich, Switzerland. E-mail: Malcolm.Kabluewin.ch

ABSTRACT Chronic obstructive pulmonary disease (COPD) is associated with increased cardiovascular mortality. Endothelial dysfunction may underpin this association. This cross-sectional study aimed to determine the impact of airflow obstruction, systemic inflammation, oxidative stress, sympathetic activation, hypoxaemia and physical activity on endothelial function in COPD.

In stable COPD patients, assessments of endothelial function by flow-mediated dilatation (FMD), cardiovascular risk (Pocock score), airflow obstruction (forced expiratory volume in $1 \mathrm{~s}$ (FEV1)), systemic inflammation (high-sensitivity C-reactive protein and interleukin-6), oxidative stress (malondialdehyde), sympathetic activation (baroreflex sensitivity), hypoxaemia (arterial oxygen tension), hypercapnia (arterial carbon dioxide tension $\left(\mathrm{PaCO}_{2}\right)$ ), physical activity (steps per day) and exercise capacity (6-min walking distance) were performed. Associations between FMD and potential determinants were assessed in univariate and multivariate analyses.

106 patients (Global Initiative for Chronic Obstructive Lung Disease stage I/II 35\%, stage III 25\% and stage IV 40\%) were included. In multivariate analysis FEV1 was positively associated with FMD, independent of other significant FMD determinants from univariate analysis (sex, smoking, combined inhaled long-acting $\beta$-adrenergic and steroid medication, heart rate, baroreflex sensitivity and $\mathrm{PaCO}_{2}$ ) and adjusted for potential confounders (cardiovascular risk and age). In addition, the FMD and FEV1 association was modified by physical activity.

The findings of this study demonstrate that the severity of airflow obstruction is a significant determinant of endothelial function in patients with COPD. A high level of physical activity seems to have a favourable effect on this association.

@ERSpublications

In COPD, the association between airflow obstruction and impaired endothelial function is modified by physical activity http://ow.ly/o84r9

This article has supplementary material available from www.erj.ersjournals.com

Earn CME accreditation by answering questions about this article. You will find these at the back of the printed copy of this issue or online at www.erj.ersjournals.com/misc/cmeinfo.xhtml

Received: Sept 122012 | Accepted after revision: Jan 142013 | First published online: Feb 212013

Conflict of interest: None declared.

Copyright @ERS 2013 


\section{Introduction}

Cardiovascular disease plays an important role concerning morbidity and mortality in patients with chronic obstructive pulmonary disease (COPD) [1]. In prospective population-based studies, the degree of airflow limitation was an independent predictor of cardiovascular events, implying a causal relationship between airflow obstruction and cardiovascular disease $[2,3]$. Although smoking is an established risk factor for both atherosclerosis and COPD, epidemiological studies have revealed that the increased cardiovascular risk in COPD patients seems to be independent of smoking habits $[3,4]$. The mechanisms underlying the relationship between COPD and cardiovascular disease are currently unclear. Multiple causal factors leading to vessel wall damage and atherosclerotic plaques have been suggested, including hypoxia [5], concurrent systemic inflammation and oxidative stress $[6,7]$, sympathetic activation and physical inactivity [8].

Of these determinants, the level of physical activity seems to play a critical role. COPD patients who are regularly physically active seem to have a lower risk of both COPD-related hospital admissions and mortality [9]. Physical activity measured objectively by a multisensory armband has been shown to strongly predict all-cause mortality in COPD [10] and patients with a low level of physical activity were at higher risk for being readmitted to hospital [11]. Thus, physical inactivity is not only a disease manifestation of COPD, but also seems to play an important role in disease progression and the development of comorbidities [9]. Thus, we postulated a priori a modifying effect of physical activity on the relationship between COPD and endothelial function.

The impairment of endothelial function represents a potential pathophysiological link between COPD and cardiovascular disease. Endothelial function as assessed by flow-mediated dilatation (FMD) of the brachial artery has been shown to provide predictive information concerning the future occurrence of cardiovascular events $[12,13]$. Therefore, noninvasive measures of endothelial function are of major interest, with the anticipation that patients at risk could be identified early in the absence of clinically apparent vascular disease $[14,15]$.

In the present study, our objective was to investigate potential determinants of endothelial function, including hypoxia, systemic inflammation, oxidative stress, sympathetic activation and physical activity in a cohort of patients with COPD.

\section{Methods \\ Subjects}

216 patients were screened for eligibility and recruited during ambulatory visits at Zurich University Hospital (Zurich, Switzerland). Consecutive patients aged 40-75 years with objectively confirmed COPD according to Global Initiative for Chronic Obstructive Lung Disease (GOLD) guidelines [16] were included.

Patients were excluded if they had suffered from an exacerbation of COPD within the last 6 weeks, had a malignancy or a coexisting pulmonary or systemic inflammatory disease. Patients were also excluded if they were taking oral corticosteroids or if they suffered from mental or physical disability precluding informed consent or compliance with the protocol.

The study was conducted in accordance with the Declaration of Helsinki of the World Medical Association. The research ethics committee of the University Hospital of Zurich approved the study (EK-ZH-NR: 1734) and all subjects gave written informed consent to participate.

\section{Study protocol}

For ethical reasons neither inhaled nor systemic medication was witheld during the study. Patients were asked to abstain from alcohol, tobacco and caffeine on the day the measurements were performed. Use of inhaled short-acting $\beta$-agonists was discouraged before measurements of cardiovascular function were taken on the day of the study.

The studies were undertaken in a temperature-controlled room with the study subject in a resting supine position for $\geqslant 10 \mathrm{~min}$ before measurements began. First, arterial blood pressure and baroreflex sensitivity were measured. Assessment of FMD was performed thereafter (after $\geqslant 20-30 \mathrm{~min}$ of rest), followed by lung function testing.

\section{Measurements}

Assessment of endothelial function by FMD of the brachial artery

FMD measurements were performed by ultrasonography according to the method originally described by CELERMAJER et al. [14]. Longitudinal images of the brachial artery were obtained with a high-frequency $(10.0 \mathrm{MHz})$ ultrasound scanning probe proximal to the antecubital fossa. Two-dimensional images, 
acquired with ECG gating, were obtained at baseline using Doppler ultrasound imaging to assess arterial diameter and flow velocity. Reactive hyperaemia was then induced by the inflation of a pneumatic tourniquet around the forearm to $200 \mathrm{mmHg}$ for $5 \mathrm{~min}$, and repeated arterial diameter and flow velocity measurements were made at maximal dilatation $60 \mathrm{~s}$ after cuff deflation. To assess endothelial-independent vasodilatation, the maximal diameter of the brachial artery $3 \mathrm{~min}$ after a single sublingual dose of nitroglycerin (NTG) (0.5 mg) was measured. All measurements were stored digitally and analysed offline. Brachial artery diameter was measured automatically at the onset of the $\mathrm{R}$ wave using dedicated software (Vascular Research Tools 5; Medical Imaging Applications LLC, Coralville, IA, USA). The mean values of at least three cardiac cycles were averaged for each time point and results of endothelial-dependent (FMD) and endothelial-independent (NTG) vasodilatation were expressed as percentage change in arterial diameter from the baseline diameter.

\section{Blood pressure, heart rate and baroreflex sensitivity}

Blood pressure and heart rate were measured in triplicate separated by 1 -min intervals after resting in a supine position for $5 \mathrm{~min}$ with a validated, semi-automated oscillometric device (Omron Healthcare, Kyoto, Japan). Baroreflex sensitivity is a measure of the capability to increase parasympathic tone and to decrease sympathetic activity in response to an increase in blood pressure. To assess baroreflex sensitivity, noninvasive continuous beat-to-beat finger blood pressure and heart rate were measured over 5 min in the supine position and recorded with a Finapres device (Finometer-Midi; Finapres Medical Systems, Amsterdam, the Netherlands). Baroreflex sensitivity was automatically quantified by analysis of the changes in pulse rate in response to changes in blood pressure with designated software (BeatScope, Version 1.1a; Finapres Medical Systems), as previously described [17].

\section{Blood analysis}

Measurements of high-sensitivity C-reactive protein (hsCRP), interleukin (IL)-6 and malondialdehyde were performed on plasma samples that were stored at $-80^{\circ} \mathrm{C}$. Particle-enhanced immunonephelometry was used to measure hsCRP. IL-6 and malondialdehyde were measured using ELISA kits (see the online supplementary material).

\section{Assessment of cardiovascular risk}

A cardiovascular risk score (Pocock score) was used to assess objectively each individual's 5-year risk of death due to cardiovascular events (see the online supplementary material) [18].

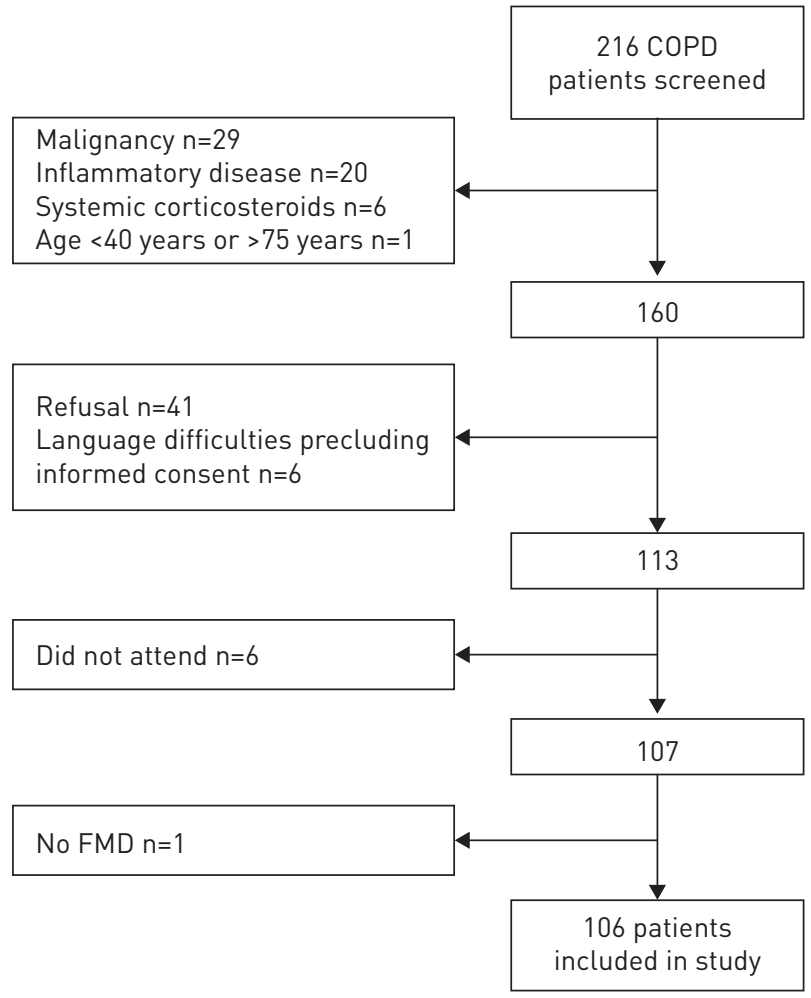

FIGURE 1 Study flow. COPD: chronic obstructive pulmonary disease; FMD: flow-mediated dilatation. 
All patients

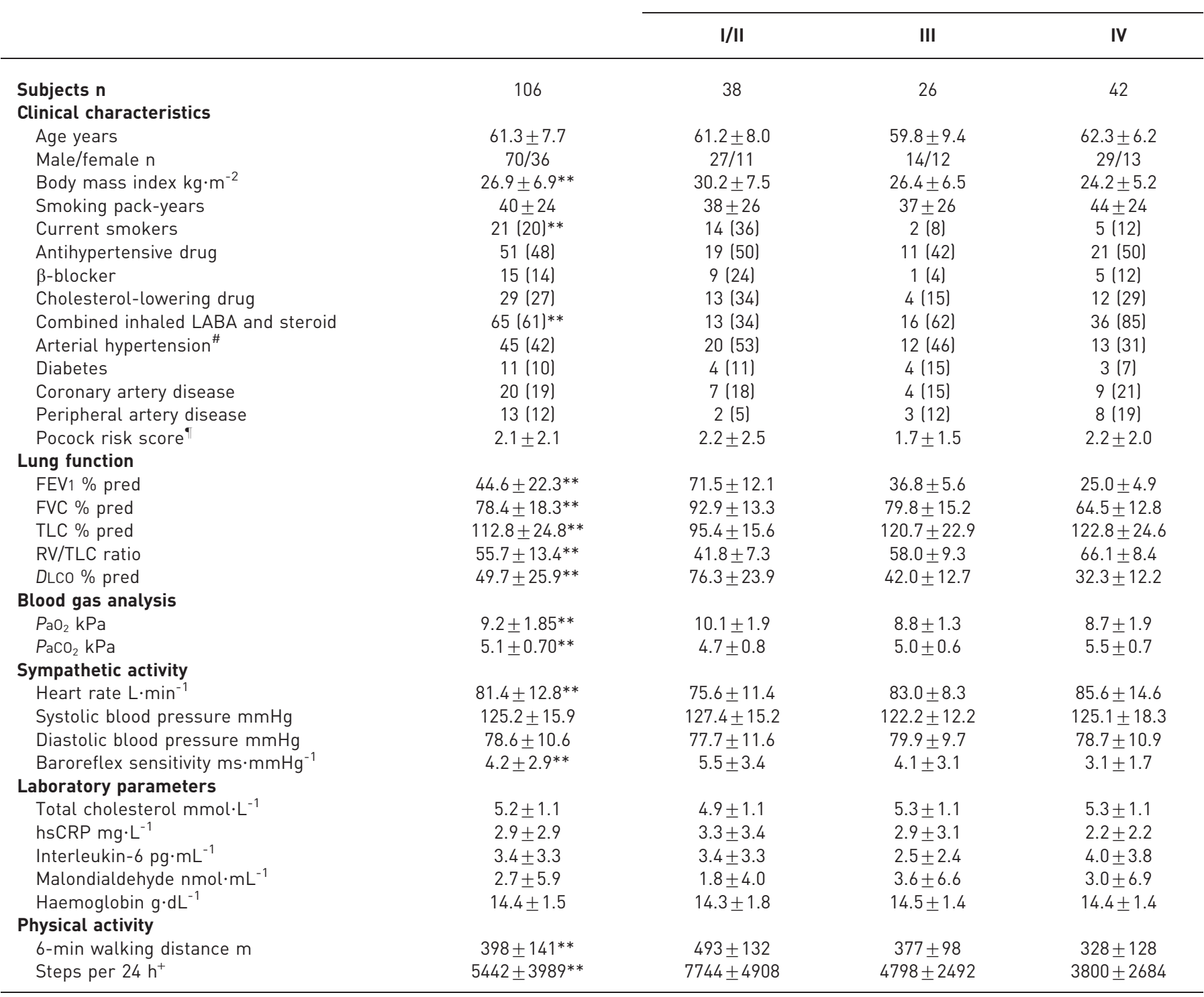

Data are presented as mean \pm SD or $n(\%)$, unless otherwise stated. GOLD: Global Initiative for Chronic Obstructive Lung Disease; LABA: long-acting $\beta_{2}$-agonist; FEV1: forced expiratory volume in $1 \mathrm{~s} ; \%$ pred: \% predicted; FVC: forced vital capacity; TLC: total lung capacity; RV: residual volume; DLCO: diffusing capacity of the lung for carbon monoxide; $\mathrm{PaO}_{2}$ : arterial oxygen tension; $\mathrm{PaCO}_{2}$ : arterial carbon dioxide tension; hsCRP: highsensitivity C-reactive protein. ${ }^{\#}$ : blood pressure $\geqslant 140 / 90 \mathrm{mmHg}$; : approximated percentage risk of 5-year mortality from cardiovascular disease; ${ }^{+}$: mean number of steps walked per $24 \mathrm{~h}$ in seven consecutive days. ${ }^{* *}: \mathrm{p}<0.01$ for comparison of differences between groups.

\section{Physical activity}

Performance-based daily physical activity (steps per $24 \mathrm{~h}$ ) was assessed using a multisensory armband (SenseWear-Pro armband; BodyMedia, Inc., Pittsburgh, PA, USA), which was worn on the upper arm for seven consecutive days except when the device had to be taken off for showering/bathing. The activity monitor has previously been used in similar settings $[19,20]$. The armband incorporates a biaxial accelerometer that records the number of steps per day [21]. Exercise capacity was assessed by the 6-min walk test (6MWT), performed according to American Thoracic Society guidelines [22].

\section{Data analysis and statistics}

Results are shown as mean $\pm \mathrm{SD}$, unless otherwise stated. Differences in baseline characteristics between groups were assessed by F-test and Chi-squared tests as appropriate. Univariate regression was used to 
investigate relationships between FMD and airflow obstruction as well as associations with the postulated underlying mechanisms. Further multivariate analysis involved regression of variables that showed a univariate p-value of $<0.1$ with adjustment for potential confounders (age, Pocock score and baseline brachial artery diameter). Multiple imputation with chained equations were used to handle missing values ( $<5 \%$ for all variables, except malondialdehyde $17 \%$, steps per $24 \mathrm{~h} 13 \%$ and baroreflex sensitivity $10 \%$ ). An indicator variable was created for malondialdehyde as a marker of oxidative stress. To investigate a modifying effect of physical activity on the association between FMD and forced expiratory volume in $1 \mathrm{~s}$ (FEV1), an interaction term (physical activity $\times$ FEV1) was included in the regression analysis. Beside this $a$ priori-stated hypothesised interaction, we did not assess any other interactions.

\section{Results}

\section{Study participants}

Of the 216 patients screened for eligibility, 106 entered the analysis (fig. 1). Patient characteristics are shown in table 1 . The prevalence of cardiovascular comorbidities was high (53\%).

\section{Endothelial function and airflow obstruction in COPD}

Endothelial function as assessed by FMD was associated with post-bronchodilator FEV1 \% predicted $(\beta=0.04, p<0.01$ ) (fig. $2 a)$. Mean \pm SD FMD in patients with GOLD stage I/II was $4.3 \pm 2.0 \%$ pred and was progressively impaired in patients with stage III $(2.8 \pm 1.5 \%$ pred) and stage IV $(2.0 \pm 1.3 \%$ pred $)$ (table 2$)$.

\section{Potential determinants influencing endothelial function}

Sympathetic activation

Impaired baroreflex sensitivity was associated with $\operatorname{FMD}(\beta=0.15, p=0.03)$, whereas the association between heart rate and FMD did not reach statistical significance $(\beta=-0.02, p=0.09)$. Baroreflex sensitivity showed an association with FEV1 \% pred $(\beta=0.37, \mathrm{p}<0.01)$ (fig. 3 ).

\section{Effect of arterial blood gases}

Arterial carbon dioxide tension $\left(\mathrm{PaCO}_{2}\right)$ was inversely associated with FMD $(\beta=-0.74, \mathrm{p}<0.01)$, whereas no association was found between hypoxaemia and FMD.

\section{Systemic inflammation and oxidative stress}

Levels of hsCRP, IL-6 and malondialdehyde were not statistically significantly associated with FMD (table 3).

\section{Physical activity and endothelial function in COPD}

Exercise capacity assessed by the 6MWT was statistically significantly associated with FMD $(\beta=0.004, p<0.01)$, and daily physical activity (steps per $24 \mathrm{~h}$ ) showed an association at $\mathrm{p}<0.1\left(\beta=8.52 \times 10^{-5}, \mathrm{p}=0.067\right)$.
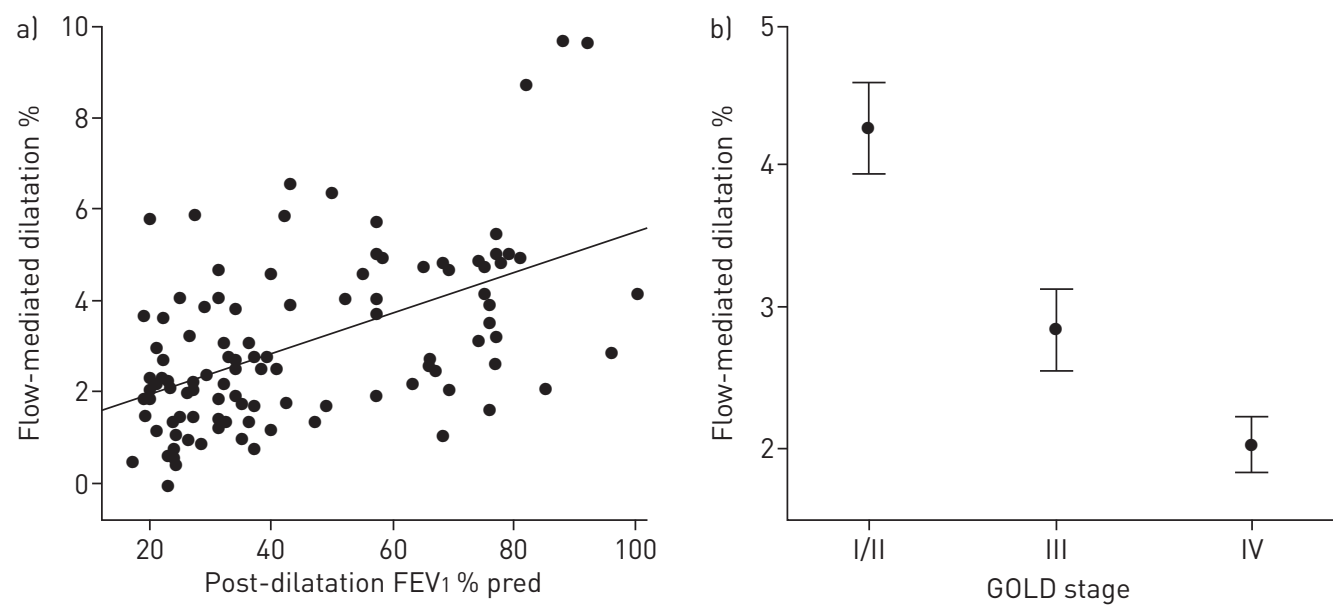

FIGURE 2 a) Univariate regression between flow-mediated dilatation (FMD) and forced expiratory volume in $1 \mathrm{~s}$ (FEV1) $\%$ predicted (\% pred); b) FMD measurements of all patients with chronic obstructive pulmonary disease grouped according to Global Initiative for Chronic Obstructive Lung Disease (GOLD) stages. Bars represent SEM. 
GOLD stage

\begin{tabular}{|c|c|c|c|c|}
\hline & & & & \\
\hline & & $I / I I$ & III & IV \\
\hline Subjects $\mathrm{n}$ & 106 & 38 & 26 & 42 \\
\hline Baseline brachial artery diameter $\mathrm{mm}$ & $3.7 \pm 0.7$ & $3.9 \pm 0.7$ & $3.6 \pm 0.7$ & $3.9 \pm 0.7$ \\
\hline Post-occlusion brachial artery flow $\mathrm{m} \cdot \mathrm{s}^{-1}$ & $0.57 \pm 0.24$ & $0.54 \pm 0.22$ & $0.55 \pm 1.8$ & $0.62 \pm 0.30$ \\
\hline FMD $\%$ & $3.0 \pm 1.9$ & $4.3 \pm 2.0$ & $2.8 \pm 1.5$ & $2.0 \pm 1.3$ \\
\hline NMD \% & $12.6 \pm 5.7$ & $12.1 \pm 4.8$ & $12.9 \pm 7.4$ & $12.9 \pm 5.6$ \\
\hline
\end{tabular}

Data are presented as mean \pm SD, unless otherwise stated. GOLD: Global Initiative for Chronic Obstructive Lung Disease; FMD: flow-mediated dilatation; NMD: nitroglycerine-mediated dilatation.

\section{Multiple regression model of all postulated mechanisms}

The multivariate model (table 4) included variables showing at least a moderate association (defined as $\mathrm{p}<0.1$ in the univariate analysis). To further control for potential confounding, conventional cardiovascular risk factors were additionally included in the final model regardless of the univariate results. In this multivariate model, airflow obstruction, physical activity and their interaction, as well as brachial artery diameter, were the only variables independently associated with FMD.

A stratified analysis was performed as the significant interaction term (number of steps per $24 \mathrm{~h} \times \mathrm{FEV} 1 \%$ ) assumed a modifying effect of physical activity on the association between FEV1 and FMD. Patients were categorised according to the median number of steps per $24 \mathrm{~h}$ and denominated either as physically active or inactive patients. Results of the covariance analysis demonstrating the association between FEV1 and predicted FMD (adjusted for age, sex, smoking, use of combined inhaled steroids and long-acting $\beta$-adrenergic drugs, $\mathrm{PaCO}_{2}$, baroreflex-sensitivity, heart rate, 6MWT, Pocock score and brachial artery diameter) within subgroups are displayed graphically in figure 4. Compared to the active patient group, results in inactive patients showed a stronger association between FEV1 and FMD.

\section{Discussion}

This study investigated potential determinants of endothelial function in COPD patients. We demonstrated a strong cross-sectional relationship between endothelial function measured by FMD and the severity of airflow obstruction across a heterogeneous group of COPD patients. Analysis of possible underlying factors revealed that only FEV1 and physical activity showed an independent effect on endothelial function. Subgroup analysis suggested a more pronounced effect of FEV1 on endothelial function in physically less active patients.

There is preliminary evidence that COPD is associated with endothelial dysfunction [23, 24]. Hence, impairment of endothelial function may represent a mechanism through which COPD leads to

FIGURE 3 The relationship between baroreflex sensitivity and airflow obstruction (forced expiratory volume in $1 \mathrm{~s}$ ). Baroreflex sensitivity was nearly normal in chronic obstructive pulmonary disease patients with Global Initiative for Chronic Obstructive Lung Disease (GOLD) stage I/ II, but was progressively impaired in patients with stage III and stage IV.

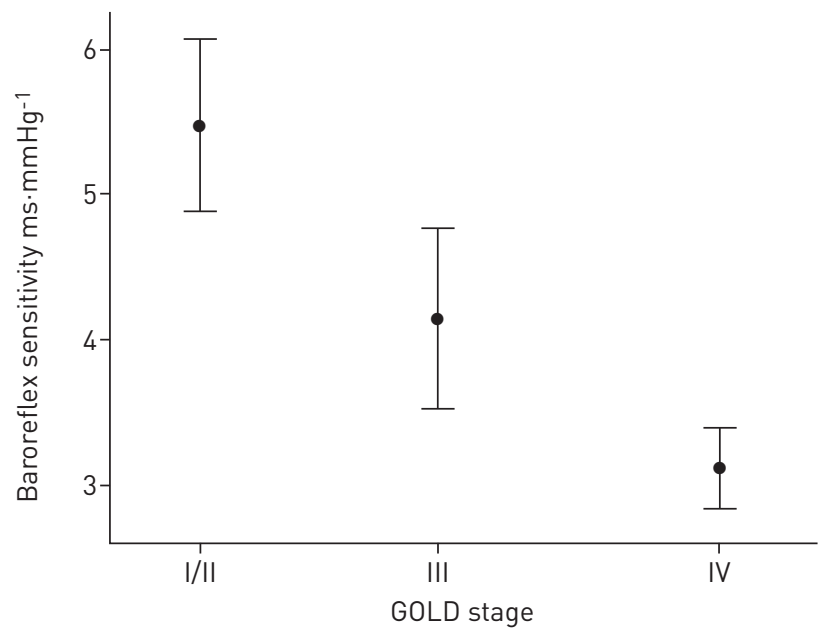


TABLE 3 Univariate regression analysis of factors potentially associated with endothelial function (measured by flow-mediated dilatation)

B-coefficient $\quad 95 \% \mathrm{Cl} \quad$ p-value

\begin{tabular}{|c|c|c|c|}
\hline \multicolumn{4}{|l|}{ Clinical characteristics } \\
\hline Age years & -0.32 & $-0.08-0.01$ & 0.173 \\
\hline Male & -0.74 & $-1.4-0.01$ & 0.055 \\
\hline Body mass index $\mathrm{kg} \cdot \mathrm{m}^{-2}$ & 0.01 & $-0.05-0.06$ & 0.818 \\
\hline Smoking pack-years & -0.01 & $-0.02-0.01$ & 0.361 \\
\hline Current smoking & 1.23 & $0.36-2.10$ & 0.006 \\
\hline Antihypertensive drug & -1.57 & $-0.89-0.57$ & 0.669 \\
\hline$\beta$-blocker & -0.18 & $-1.20-0.84$ & 0.726 \\
\hline Cholesterol-lowering drug & -0.15 & $-0.96-0.66$ & 0.718 \\
\hline Combined inhaled LABA and steroid & -0.78 & $-1.52--0.43$ & 0.038 \\
\hline Total cholesterol $\mathrm{mmol} \cdot \mathrm{L}^{-1}$ & -0.04 & $-0.38-0.30$ & 0.827 \\
\hline Pocock risk score & -0.12 & $-0.30-0.06$ & 0.186 \\
\hline \multicolumn{4}{|l|}{ Lung function } \\
\hline FEV $1 \%$ pred & 0.04 & $0.03-0.06$ & $<0.01$ \\
\hline FVC \% pred & 0.04 & $0.02-0.06$ & $<0.01$ \\
\hline TLC \% pred & -0.01 & $-0.02-0.01$ & 0.389 \\
\hline $\mathrm{RV} / \mathrm{TLC}$ ratio $\%$ & -0.05 & $-0.07--0.02$ & $<0.01$ \\
\hline DLCO \% pred & 0.02 & $0.01-0.03$ & $<0.01$ \\
\hline \multicolumn{4}{|l|}{ Blood gases } \\
\hline $\mathrm{PaO}_{2} \mathrm{kPa}$ & 0.10 & $-0.10-0.30$ & 0.331 \\
\hline $\mathrm{PaCO}_{2} \mathrm{kPa}$ & -0.74 & $-1.23--0.24$ & $<0.01$ \\
\hline \multicolumn{4}{|l|}{ Sympathetic activity } \\
\hline Heart rate $L \cdot \min ^{-1}$ & -0.02 & $-0.05-0.00$ & 0.088 \\
\hline Systolic blood pressure mmHg & 0.00 & $-0.03-0.02$ & 0.776 \\
\hline Diastolic blood pressure $\mathrm{mmHg}$ & 0.00 & $-0.03-0.03$ & 0.983 \\
\hline Baroreflex sensitivity $\mathrm{ms} \cdot \mathrm{mmHg}^{-1}$ & 0.15 & $0.02-0.28$ & 0.027 \\
\hline \multicolumn{4}{|l|}{ Systemic inflammation and oxidative stress } \\
\hline $\mathrm{hsCRP} \mathrm{mg} \cdot \mathrm{L}^{-1}$ & 0.01 & $-0.01-0.04$ & 0.270 \\
\hline Interleukin-6 pg $\cdot \mathrm{mL}^{-1}$ & 0.02 & $-0.09-0.13$ & 0.664 \\
\hline Malondialdehyde $\mathrm{nmol}^{-} \mathrm{mL}^{-1}$ & -0.33 & $-1.08-0.41$ & 0.376 \\
\hline \multicolumn{4}{|l|}{ Physical activity } \\
\hline 6-min walking distance $\mathrm{m}$ & 0.004 & $0.00-0.01$ & 0.001 \\
\hline Steps per $24 \mathrm{~h}^{+}$ & $8.52 \times 10^{-5}$ & $-6.23 \times 10^{-6}-1.77 \times 10^{-4}$ & 0.067 \\
\hline
\end{tabular}

LABA: long-acting $\beta_{2}$-agonist; FEV1: forced expiratory volume in $1 \mathrm{~s} ; \%$ pred: $\%$ predicted; FVC: forced vital capacity; TLC: total lung capacity; RV: residual volume; DLCO: diffusing capacity of the lung for carbon monoxide; $\mathrm{PaO}_{2}$ : arterial oxygen tension; $\mathrm{PaCO}_{2}$ : arterial carbon dioxide tension; hsCRP: high-sensitivity C-reactive protein. ${ }^{\#}$ : approximated percentage risk of 5-year mortality from cardiovascular disease; ": implemented as an indicator variable with a threshold of $0.16 \mathrm{nmol} \cdot \mathrm{mL}^{-1}$; ${ }^{+}$: average number of steps walked per $24 \mathrm{~h}$ in a measurement period of seven consecutive days.

cardiovascular disease. However, data on potential biological factors underpinning the association between COPD and endothelial function, such as hypoxia, systemic inflammation, oxidative stress, sympathetic activation and physical activity, are mostly lacking. Therefore, our aim was to identify alterations in endothelial function in COPD and characterise the impact of various mechanisms potentially underpinning this association.

BARR et al. [24] investigated 107 former smokers, of whom 40\% suffered from COPD. The authors observed a relationship between FMD and FEV1, as well as with percentage of lung emphysema. In a study by EICKHOFF et al. [25], 60 patients with mild-to-moderate COPD were compared to smoking and nonsmoking control subjects without COPD. The authors found that FMD was significantly impaired in patients with COPD compared to smoking and nonsmoking control subjects without COPD. In contrast to our study, FMD values in patients with COPD were considerably higher in the study by EICKHOFF et al. [25], which might be due to differences in the measurement techniques, as the sphygmanometer cuff was placed around the upper arm instead of the forearm as recommended [26]. In contrast to our findings and those of EICKHOFF et al. [25], MACLAY et al. [27] presented a case-control study that assessed vascular function in 18 COPD patients and smoking control subjects without COPD. The authors of the latter small study did not 
TABLE 4 Multivariate analysis of determinants of flow-mediated dilatation and potential confounders

\begin{tabular}{|c|c|c|c|}
\hline & $\beta$-coefficient & $95 \% \mathrm{Cl}$ & p-value \\
\hline Age years & $-2.0 \times 10^{-3}$ & $-0.06-0.05$ & 0.941 \\
\hline Male & -0.07 & $-0.90-0.77$ & 0.877 \\
\hline Combined inhaled LABA and steroid & 0.08 & $-0.66-0.81$ & 0.840 \\
\hline Pocock risk score & $2.4 \times 10^{-3}$ & $-0.22-0.22$ & 0.983 \\
\hline FEV $1 \%$ pred & 0.08 & $0.04-0.11$ & $<0.01$ \\
\hline Baroreflex sensitivity $\mathrm{ms} \cdot \mathrm{mmHg}^{-1}$ & 0.09 & $-0.7-0.26$ & 0.268 \\
\hline 6-min walking distance $\mathrm{m}$ & $-1.3 \times 10^{-3}$ & $-4.6 \times 10^{-3}-1.9 \times 10^{-3}$ & 0.409 \\
\hline Steps per $24 \mathrm{~h}^{\circ}$ & $3.5 \times 10^{-4}$ & $7.3 \times 10^{-5}-6.1 \times 10^{-4}$ & 0.014 \\
\hline Steps per 24 h $\times$ FEV $1 \%$ & $-5.9 \times 10^{-6}$ & $-1.1 \times 10^{-5}--7.7 \times 10^{-7}$ & 0.025 \\
\hline Brachial artery diameter $\mathrm{mm}$ & -0.68 & $-1.25--0.11$ & 0.019 \\
\hline
\end{tabular}

LABA: long-acting $\beta_{2}$-agonist; FEV1: forced expiratory volume in $1 \mathrm{~s} ; \%$ pred: \% predicted; $\mathrm{PaCO}_{2}$ : arterial carbon dioxide tension. ${ }^{\#}$ : approximated percentage risk of 5 -year mortality from cardiovascular disease; ${ }^{\circ}$ : average number of steps walked per $24 \mathrm{~h}$ in seven consecutive days.

observe differences in endothelial function between the two groups. However, MACLAY et al. [27] used venous occlusion plethysmography with infusion of endothelium-dependent vasodilators as an assessment of endothelial function, so the studies are not directly comparable. In addition, the study by MACLAY et al. [27] may not have been appropriately powered to exclude clinically significant differences in endothelial function between the studied groups.

Our results extend the findings of previous studies by rigorously analysing potential determinants underpinning the relationship between impaired endothelial function and COPD. EICKHOFF et al. [25] reported that higher levels of CRP, but not IL-6, were associated with a lower FMD in a group of 60 COPD patients, suggesting that systemic inflammation may play a role in the pathogenesis of endothelial dysfunction in COPD. In the present larger study, hsCRP and IL-6 did not affect the relationship between FMD and airflow obstruction in COPD patients. A possible explanation for the conflicting findings could be that patients included in the study by EICKHOFF et al. [25] were free from comorbidities, whereas we included typical COPD patients, some of whom had diabetes and cardiovascular disease, factors that are known to be associated with systemic inflammation, and thus may have masked an effect of COPD on inflammatory markers [28].

COPD has been shown to be associated with increased oxidative stress markers such as reactive oxygen species [29]. Oxidative activity can be determined by measuring oxidative products of lipid peroxidation, such as malondialdehyde, which is considered to be a reliable measure of oxidative stress [30]. However, to date there have been no data from clinical studies investigating the relationship between oxidative stress burden and endothelial function in patients with COPD. In the present study, levels of malondialdehyde showed no association with FMD, suggesting that oxidative stress assessed in blood may not play a predominant role in determining endothelial function in patients with COPD.

Consistent with autonomic sympathetic activation, elevated heart rate [31], reduced heart rate variability [32] and depressed baroreflex sensitivity [33] have been described in COPD patients. However, there have been no data as to whether sympathetic activation leads to an impairment of endothelial function in COPD. In the present study, elevated heart rate and reduced baroreflex sensitivity both showed a significant relationship with the severity of airflow obstruction. Although we could demonstrate a moderate association between baroreflex sensitivity and FMD in the univariate analysis, no significant independent association remained after implementation in the multivariate analysis. Therefore, sympathetic activity seems not to be a predominant determinant of endothelial function in COPD.

Patients with COPD often develop hypoxaemia, which may be present intermittently (e.g. during exercise or sleep) or may be sustained in more severe cases. It has been suggested that hypoxia is associated with a number of pro-atherogenic effects, including systemic inflammation [5], oxidative stress [34] and an increase of blood pressure [35]. However, the effects of hypoxia on endothelial function in patients with COPD have not been studied. Our results imply that hypoxia seems not to promote impairment of 

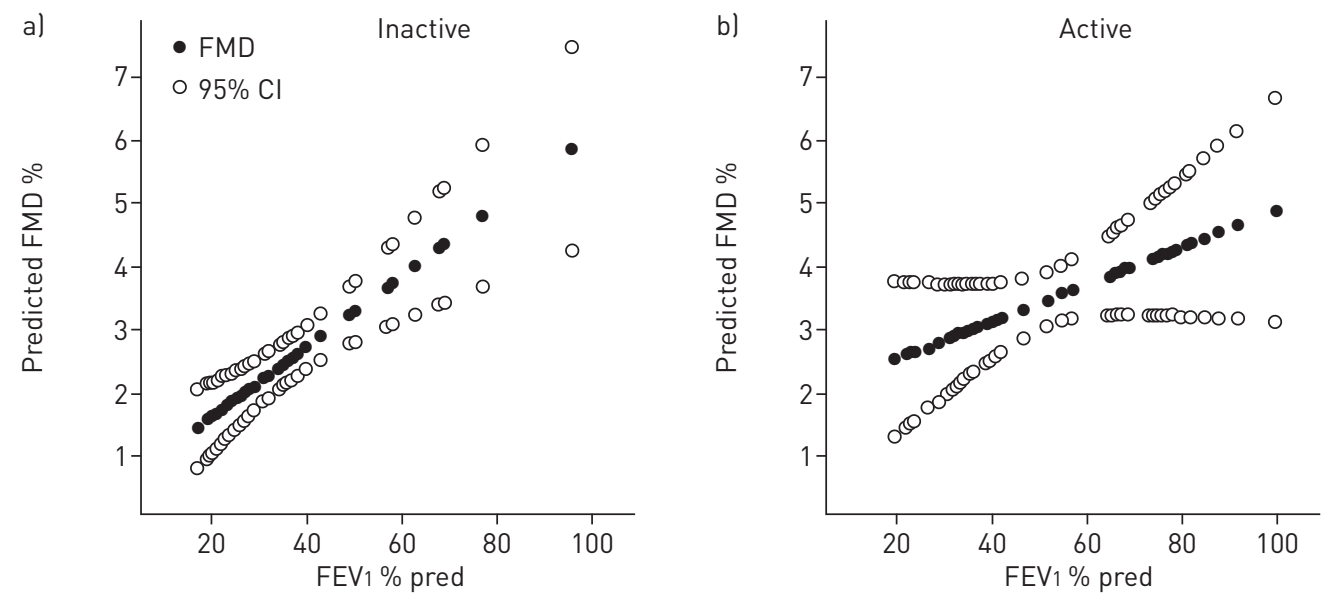

FIGURE 4 Predicted flow-mediated dilatation (FMD) within 95\% CI in relation to the forced expiratory volume in $1 \mathrm{~s}$ (FEV1) \% predicted (\% pred) for a) inactive and b) active patients. Patients were classified according to their level of daily physical activity: below and above the median number of steps per day were classified as inactive and active, respectively. Analysis of covariance was used to predict FMD after controlling for diameter of the brachial artery, age, sex, current smoking, use of combined inhaled steroids and long-acting $\beta$-adrenergic drugs, arterial carbon dioxide tension, baroreflex sensitivity, heart rate, 6-min walk test and Pocock score. There was a significant association between FMD and FEV1 in inactive patients (adjusted $\beta=0.06, p<0.01$ ) compared to the active patients (adjusted $\beta=0.03, p=0.11$ ), suggesting a modifying effect of physical fitness on the association between FMD and FEV1.

endothelial function in COPD. However, hypercapnia showed a relationship with reduced FMD in univariate analysis, although this effect disappeared after correction for airflow obstruction.

Various studies in animal models and humans demonstrated the impact of physical activity on endothelial function $[36,37]$. It has been postulated that physical activity leads to shear stress on the arterial wall, causing increased expression of endothelial nitric oxide synthase, thus improving endothelial vasomotor function. In the current study, a significant modifying effect of physical activity on endothelial function was found (fig. 4). Patients with severe airflow obstruction who were physically active were less prone to more severe impairment of FMD, compared to inactive COPD patients with severe airflow obstruction. Of the studied determinants with potential impact on the association of airflow obstruction and FMD, only physical activity demonstrated an independent effect. These results suggest that physical activity may attenuate the progression of vascular dysfunction in COPD. However, this needs to be proven in welldesigned interventional studies.

Although there is accumulating evidence from large epidemiological studies that impaired lung volumes may be important predictors of future cardiovascular events $[2,3]$, this has not been widely recognised and thus lung volumes have not been implemented in cardiovascular risk scores such as the Pocock score. In the current study, there was no relationship between the Pocock risk score and FMD. Thus, it seems that FEV1 and the level of daily physical activity may be more important determinants of endothelial function in patients with COPD than the combined conventional factors implemented in the Pocock score.

The main limitation of the present study is the cross-sectional design, which does not allow the establishment of a causal relationship. A prospective cohort study would provide stronger evidence because the temporal relationship as a key element of causal inference could be determined. A randomised trial may be more difficult, as both physical activity and lung function are difficult to modify, at least in the short term. However, it may be that future large and long-term randomised trials that aim at modifying physical activity will provide more evidence. A further limitation is that we had three variables with $>5 \%$ missing values, including malondialdehyde (17\%), steps per $24 \mathrm{~h}(13 \%)$ and baroreflex sensitivity (10\%). Finally, for ethical reasons, (inhaled) drugs were not withheld during the study; therefore, we cannot entirely exclude that the relationship between FEV1 and FMD is driven by differences in $\beta$-agonist use rather than the severity of airflow limitation. However, by including the use of $\beta$-agonists and baroreflex sensitivity as covariates in the multivariate analysis, appropriate correction for this possible bias can be assumed.

In conclusion, the findings of this study demonstrate that the severity of airflow obstruction is a significant determinant of endothelial function in patients with COPD. A high level of physical activity seems to have a favourable effect on this association. 


\section{References}

1 McGarvey LP, John M, Anderson JA, et al. Ascertainment of cause-specific mortality in COPD: operations of the TORCH Clinical Endpoint Committee. Thorax 2007; 62: 411-415.

2 Engström G, Melander O, Hedblad B. Population-based study of lung function and incidence of heart failure hospitalisations. Thorax 2010; 65: 633-638.

3 Sin DD, Wu L, Man SF. The relationship between reduced lung function and cardiovascular mortality: a population-based study and a systematic review of the literature. Chest 2005; 127: 1952-1959.

4 Curkendall SM, DeLuise C, Jones JK, et al. Cardiovascular disease in patients with chronic obstructive pulmonary disease, Saskatchewan Canada: cardiovascular disease in COPD patients. Ann Epidemiol 2006; 16: 63-70.

5 Sabit R, Thomas P, Shale DJ, et al. The effects of hypoxia on markers of coagulation and systemic inflammation in patients with COPD. Chest 2010; 138: 47-51.

6 Sin DD, Man SF. Chronic obstructive pulmonary disease: a novel risk factor for cardiovascular disease. Can J Physiol Pharmacol 2005; 83: 8-13.

7 MacNee W. Pulmonary and systemic oxidant/antioxidant imbalance in chronic obstructive pulmonary disease. Proc Am Thorac Soc 2005; 2: 50-60.

8 Watz H, Waschki B, Boehme C, et al. Extrapulmonary effects of chronic obstructive pulmonary disease on physical activity: a cross-sectional study. Am J Respir Crit Care Med 2008; 177: 743-751.

9 Garcia-Aymerich J, Lange $\mathrm{P}$, Benet $\mathrm{M}$, et al. Regular physical activity reduces hospital admission and mortality in chronic obstructive pulmonary disease: a population based cohort study. Thorax 2006; 61: 772-778.

10 Waschki B, Kirsten A, Holz O, et al. Physical activity is the strongest predictor of all-cause mortality in patients with COPD: a prospective cohort study. Chest 2011; 140: 331-342.

11 Pitta F, Troosters T, Probst VS, et al. Physical activity and hospitalization for exacerbation of COPD. Chest 2006; 129: 536-544.

12 Rubinshtein R, Kuvin JT, Soffler M, et al. Assessment of endothelial function by non-invasive peripheral arterial tonometry predicts late cardiovascular adverse events. Eur Heart J 2010; 31: 1142-1148.

13 Lind L, Berglund L, Larsson A, et al. Endothelial function in resistance and conduit arteries and 5-year risk of cardiovascular disease. Circulation 2011; 123: 1545-1551.

14 Celermajer DS, Sorensen KE, Gooch VM, et al. Non-invasive detection of endothelial dysfunction in children and adults at risk of atherosclerosis. Lancet 1992; 340: 1111-1115.

15 Gokce N, Keaney JF Jr, Hunter LM, et al. Risk stratification for postoperative cardiovascular events via noninvasive assessment of endothelial function: a prospective study. Circulation 2002; 105: 1567-1572.

16 Rabe KF, Hurd S, Anzueto A, et al. Global strategy for the diagnosis, management, and prevention of chronic obstructive pulmonary disease: GOLD executive summary. Am J Respir Crit Care Med 2007; 176: 532-555.

17 Westerhof BE, Gisolf J, Stok WJ, et al. Time-domain cross-correlation baroreflex sensitivity: performance on the EUROBAVAR data set. J Hypertens 2004; 22: 1371-1380.

18 Pocock SJ, McCormack V, Gueyffier F, et al. A score for predicting risk of death from cardiovascular disease in adults with raised blood pressure, based on individual patient data from randomised controlled trials. BMJ 2001; 323: $75-81$.

19 Waschki B, Spruit MA, Watz H, et al. Physical activity monitoring in COPD: compliance and associations with clinical characteristics in a multicenter study. Respir Med 2012; 106: 522-530.

20 Watz H, Waschki B, Meyer T, et al. Physical activity in patients with COPD. Eur Respir J 2009; 33: 262-272.

21 Van Remoortel H, Raste Y, Louvaris Z, et al. Validity of six activity monitors in chronic obstructive pulmonary disease: a comparison with indirect calorimetry. PLoS One 2012; 7: e39198.

22 Brooks D, Solway S, Gibbons WJ. ATS statement on six-minute walk test. Am J Respir Crit Care Med 2003; 167: 1287.

23 Clarenbach CF, Thurnheer R, Kohler M. Vascular dysfunction in chronic obstructive pulmonary disease: current evidence and perspectives. Expert Rev Respir Med 2012; 6: 37-43.

24 Barr RG, Mesia-Vela S, Austin JH, et al. Impaired flow-mediated dilation is associated with low pulmonary function and emphysema in ex-smokers: the Emphysema and Cancer Action Project (EMCAP) Study. Am J Respir Crit Care Med 2007; 176: 1200-1207.

25 Eickhoff P, Valipour A, Kiss D, et al. Determinants of systemic vascular function in patients with stable chronic obstructive pulmonary disease. Am J Respir Crit Care Med 2008; 178: 1211-1218.

26 Thijssen DH, Black MA, Pyke KE, et al. Assessment of flow-mediated dilation in humans: a methodological and physiological guideline. Am J Physiol Heart Circ Physiol 2011; 300: H2-H12.

27 Maclay JD, McAllister DA, Mills NL, et al. Vascular dysfunction in chronic obstructive pulmonary disease. Am J Respir Crit Care Med 2009; 180: 513-520.

28 Magnussen $\mathrm{H}$, Watz H. Systemic inflammation in chronic obstructive pulmonary disease and asthma: relation with comorbidities. Proc Am Thorac Soc 2009; 6: 648-651.

29 Rahman I. The role of oxidative stress in the pathogenesis of COPD: implications for therapy. Treat Respir Med 2005; 4: 175-200.

30 Del Rio D, Stewart AJ, Pellegrini N. A review of recent studies on malondialdehyde as toxic molecule and biological marker of oxidative stress. Nutr Metab Cardiovasc Dis 2005; 15: 316-328.

31 Heindl S, Lehnert M, Criée CP, et al. Marked sympathetic activation in patients with chronic respiratory failure. Am J Respir Crit Care Med 2001; 164: 597-601.

32 Scalvini S, Porta R, Zanelli E, et al. Effects of oxygen on autonomic nervous system dysfunction in patients with chronic obstructive pulmonary disease. Eur Respir J 1999; 13: 119-124.

33 Haider T, Casucci G, Linser T, et al. Interval hypoxic training improves autonomic cardiovascular and respiratory control in patients with mild chronic obstructive pulmonary disease. J Hypertens 2009; 27: 1648-1654.

34 Pialoux V, Hanly PJ, Foster GE, et al. Effects of exposure to intermittent hypoxia on oxidative stress and acute hypoxic ventilatory response in humans. Am J Respir Crit Care Med 2009; 180: 1002-1009. 
35 Foster GE, Brugniaux JV, Pialoux V, et al. Cardiovascular and cerebrovascular responses to acute hypoxia following exposure to intermittent hypoxia in healthy humans. J Physiol 2009; 587: 3287-3299.

36 Hambrecht R, Adams V, Erbs S, et al. Regular physical activity improves endothelial function in patients with coronary artery disease by increasing phosphorylation of endothelial nitric oxide synthase. Circulation 2003; 107: 3152-3158.

37 Kojda G, Cheng YC, Burchfield J, et al. Dysfunctional regulation of endothelial nitric oxide synthase (eNOS) expression in response to exercise in mice lacking one eNOS gene. Circulation 2001; 103: 2839-2844. 